\title{
Drug Utilization Study of Antibiotics in Bacterial Meningitis (a Retrospective Study in Dr. Soetomo General Hospital, Surabaya, Indonesia)
}

Mareta Rindang Andarsari ${ }^{1}$, Didik Hasmono ${ }^{2}$, Samirah $^{1}$, Suharjono $^{1}$, Dea Ayu Nabilah ${ }^{1}$, Paulus Sugianto $^{2}$

${ }^{1}$ Departement of Clinical Pharmacy, Faculty of Pharmacy, Airlangga University, Surabaya

${ }^{2}$ Neurology Division, Dr. Soetomo General Hospital, Surabaya

*Corresponding author: mareta.ra@ff.unair.ac.id

\begin{abstract}
Background: Meningitis defined as an inflammation of the meninges, a membrane that surrounds the brain. The inflammation is a result from bacterial infection. Central nervous system infection is a medical emergency because of the progressivity and potentially life-threatening. Antibiotics usage become crucial to reduce morbidity and mortality. Objective: This study was aimed to assess the use of antibiotics, prescribed for patients with bacterial meningitis in Neurology Department of Dr. Soetomo General Hospital Surabaya from January 2010 until June 2015. Methods: Retrospective study using medical record of inpatients obtained from January $I^{\text {st }} 2010$ until June $30^{\text {th }}$ 2015. The inclusion criteria were inpatients with bacterial meningitis (diagnosed by physician using CT scan data, lumbal puncture and clinical signs and symptoms) and prescribed with antibiotics. Patients with antibiotics therapy less than 3 days and infection other than bacterials were excluded. Results: From 85 patients, male to female ratio was 1.66. Meningitis appear to be mostly occured in productive age, $39(45.88 \%)$ in 15 - 29 years old and $40(47.06 \%)$ in 30 - 60 years old. Number of antibiotics prescribed were 130 prescriptions, as single and combination therapy. The most prescribed antibiotic was cephalosporins (97 prescriptions), dominated by $2 \mathrm{~g}$ twice daily ceftriaxone with 86 (66.15\%) from overall prescriptions. Followed by metronidazole and fluoroquinolons, $11(8.46 \%)$ and $8(6.15 \%)$ respectively. In addition, there were 26 prescriptions of combination therapy, mostly ceftriaxone and metronidazole. Conclusion: Bacterial meningitis are mostly treated using ceftriaxone which is an appropriate drug of choice.
\end{abstract}

Keywords: antibiotics, bacterial meningitis, drug utilization study, ceftriaxone

\section{INTRODUCTION}

Bacterial meningitis is an infection of leptomeninges, a membrane surrounding the brain and spinal cord, caused by bacteries infiltration. Cerebrospinal Fluid (CSF) is a good media for organisms' growth, due to its sterility from antibodies and leukocyts, also contains isotonic glucose. Over the year, incidence of bacterial meningitis has shifted from infants (median equal to 9 months old) to adults (median equal to 25 years old) caused by widespread use of vaccines (Roos \& Beek, 2010; McIntyre et al., 2012; Tunkel et al., 2017). From 1990 to 2013, while the mortality in children under 5 years was significantly reduced, but mortality in those older only decrease 2 - 7\% (McGill et al., 2016). In adults, 18 - 50 years old, the most common pathogenic organisms are Streptococcus pneumoniae and Neisseria meningiditis. Whereas in post surgery patients, possible organisms involved are $S$. aureus and P. aeruginosa (Tunkel, 2017). Untreated bacterial meningitis can further damage neurons caused by pathogens-derived neurotoxic products. This neuronal defect can lead to permanent sequelae or death. Antibiotics serve as the main therapy which is urgently needed to overcome the disease's progressivity. Antibiotic therapy should be started as early as possible with some consideration such as antibiotic sensitivity/resistance patterns. When infection occured in the meninges, antibiotic penetration to across the Blood Brain Barrier (BBB) should be considered to ensure antibiotic effective concentration achieved (Nau et al., 2010). Other studies found that bacterial meningitis pathogens develop resistance to antibiotics. In Egypt, $40 \%$ of $N$. meningitidis are resistant to ampicillin (Shaban \& Siam, 2009). Tzanakaki \& Mastrantonio (2007) found that $24.4 \%$ of Haemophilus influenzae was resistant to ampicillin in Spain. Therefore, the proper use of antibiotic is needed to prevent antibiotic resistance. This study aimed to examine the antibiotic usage in bacterial meningitis, and this data can be use as a 
consideration in choosing the right antibiotic in bacterial meningitis patients.

\section{METHODS}

This study was conducted in neurology wards of Dr. Soetomo General Hospital, a government-owned teaching hospital located in Surabaya, Indonesia. The protocol has been granted an ethical appoval from the hospital's Ethical Commitee before the data collection conducted. Data were retrospectively acquired from the hospital's medical record center with specified inquiries for inpatients with bacterial meningitis admitted between January 1, 2010 until June 30, 2015 as the population, and then collected patients who recieved antibiotic therapy. Criteria for sample exclusion were coexisting diagnosis or suspection of meningitis other than bacterial and/or those who failed to recieve at least 3 days of antibiotic during hospitalisation. Informations assessed were age, gender, antibiotic type, dose, length of hospital stay, and discharged condition. The percentage of antibiotic prescribed was calculated as follow: (number of antibiotic type encounters/total number of encounters surveyed) x $100 \%$.

\section{RESULTS AND DISCUSSION}

There were 85 patient medical records fit the inclusion criteria. The distribution of age, gender, length of stay, and discharge conditions are shown in Table 1. In this study, bacterial meningitis was mostly occured in productive age. Elderly patients (more than 60 years old) have a risk of bacterial meningitis caused by low immunity. The differences between the results of this study and literature caused by the present of risk factors that affect patient conditions such as environment, socio-economic and food contamination (Goodwin \& Hartis, 2008; Mace, 2008). Male are dominating than female in bacterial meningitis. This may be caused by genetic reason. Male only has one $\mathrm{X}$ chromosome instead of two as in female. The $\mathrm{X}$ chromosome has genes which are involved directly or indirectly in immunoglobulin synthesis. Lack of the X chromosome causes male to be more susceptible to infections (Libert et al., 2010).

Length of stay patients is related to the duration of antibiotic administration. Duration of antibiotic administration should be based on causative bacteria that is obtained from cerebrospinal fluid culture, but not all patients agreed with lumbal puncture (Goodwin \& Hartis, 2008). So, empirical antibiotic is given to the patients based on experience of clinicians that are supported by guideline and clinical pathway in Neuroscience Department, Dr. Soetomo General Hospital.

Table 1. Age, gender distribution and length of stay

\begin{tabular}{|c|c|c|}
\hline \multicolumn{3}{|c|}{$(\mathrm{N}=85)$} \\
\hline & $\mathrm{n}$ & $\%$ \\
\hline \multicolumn{3}{|l|}{ Age (years) } \\
\hline $15-29$ & 39 & 45.88 \\
\hline $30-60$ & 40 & 47.06 \\
\hline$>60$ & 6 & 7.06 \\
\hline \multicolumn{3}{|l|}{ Gender } \\
\hline Male & 53 & 62.35 \\
\hline Female & 32 & 37.65 \\
\hline \multicolumn{3}{|l|}{$\begin{array}{l}\text { Length } \\
\text { (days) }\end{array}$} \\
\hline $3-7$ & 28 & 32.94 \\
\hline $8-14$ & 26 & 30.59 \\
\hline $15-21$ & 20 & 23.53 \\
\hline $22-28$ & 8 & 9.41 \\
\hline$>28$ & 3 & $3, .53$ \\
\hline \multicolumn{3}{|l|}{$\begin{array}{l}\text { Discharge } \\
\text { condition }\end{array}$} \\
\hline Doctor's decision & 31 & 36.47 \\
\hline Patient's request & 18 & 21.18 \\
\hline Died & 36 & 42.35 \\
\hline Total & 85 & 100 \\
\hline
\end{tabular}

From the collected data, there were 130 prescribed antibiotics found as single and as combination therapy. Cephalosporins were the most prescribed antibiotic with $74.62 \%$ of total antibiotics prescription (Table 2). Among 130 prescribed antibiotics, there were 26 prescriptions of combination antibiotics, which 8 of them were combination of ceftriaxone and metronidazole. 
Table 2. Prescribed antibiotics in bacterial meningitis

\begin{tabular}{|c|c|c|c|}
\hline Antibiotic type & Dose (daily) & Prescription & $\%$ \\
\hline Cephalosporins & & 97 & 74.62 \\
\hline Ceftriaxone & $2 \times 2 \mathrm{~g}$ & 86 & 66.15 \\
\hline Ceftazidime & $3 \times 1 \mathrm{~g}$ & 8 & 6.15 \\
\hline Cefixime & $2 \times 100 \mathrm{mg}$ & 3 & 2.31 \\
\hline Aminoglycosides & & 4 & 3.08 \\
\hline Gentamycin & $2 \times 80 \mathrm{mg}$ & 2 & 1.54 \\
\hline Amikacin & $3 \times 250 \mathrm{mg}$ & 2 & 1.54 \\
\hline Fluoroquinolones & & 8 & 6.15 \\
\hline Levofloxacin & $1 \times 750 \mathrm{mg}$ & 6 & 4.61 \\
\hline Ciprofloxacin & $2 \times 400 \mathrm{mg}$ & 2 & 1.54 \\
\hline Others & & 21 & 16.15 \\
\hline Ampicillin & $4 \times 3 g$ & 1 & 0.77 \\
\hline Meropenem & $3 \times 1 \mathrm{~g}$ & 3 & 2.31 \\
\hline Metronidazole & $3 \times 500 \mathrm{mg}$ & 11 & 8.46 \\
\hline Cotrimoxazole & $3 \times 960 \mathrm{mg}$ & 2 & 1.54 \\
\hline Fosfomycin & $2 \times 2 g$ & 3 & 2.31 \\
\hline Chloramphenicol & $4 \times 1 \mathrm{~g}$ & 1 & 0.77 \\
\hline Total & & 130 & 100 \\
\hline
\end{tabular}

Antibiotics therapy should be started immediately in bacterial meningitis. Selecting empiric antibiotics should be considering age and underlying conditions, until microbiology test obtained. Broad spectrum antibiotics such as cephalosporins are recommended for empiric therapy because they have consistent CSF penetration and potential against pathogens of bacterial meningitis (Tunkel et al., 2017). After the aetiologic pathogen had been defined from lumbal puncture, empiric antibiotics should be changed. Analizing CSF important to confirm the diagnosis and determine the pathogen and its sensitivity (Heckenberg et al., 2014). Antibiotics should be able to penetrate BBB and achieve minimum inhibitory concentration (MIC) to achieve therapeutic effect. Factors that determine their penetration into CSF are molecular weight, lipophilicity, drug-protein binding, and active transport (Nau et al., 2010).

Among various type of antibiotics used in bacterial meningitis, cephalosporins group, especially ceftriaxone, was the most widely used. Ceftriaxone is the third generation of cephalosporin with extended antibacterial spectrum, notably in Gram negative bacteria. Cephalosporins have low lipophilicity, hence the poor penetration through BBB. However, in the presence of inflammed meninges, the tight junction belt were loosen, increasing cephalosporins concentration in CSF. Moreover, the MIC of extended spectrum cephalosporins for common pathogens are generally low, but concentration in CSF is already several fold greater than needed (Lutsar \& Friedland, 2000; Prasad et al., 2013). Ceftriaxone shows a $\mathrm{CSF} /$ serum AUC ratio in non-inflammed meninges of
$<0.02$, but the presence of inflamation ensured higher CSF concentration (Paolo et al., 2013). Following cephalosporins, metronidazole was also used in bacterial meningitis in this study. Metronidazole can be used as combination with cephalosporins to expand antibacterial activity, especially anaerobes bacterial. Metronidazole is a small lipophilic molecule, penetrate into CSF well and achieve CSF concentration almost as high as the plasma concentration. Metronidazole has been proved effective for CNS anaerob infections (Nau et al., 2010; Lofmark et al., 2010).

\section{CONCLUSION}

Ceftriaxone, a cephalosporin, until June 2015 becomes the drug of choice for bacterial meningitis in Neuroscience Department, Dr. Soetomo General Hospital algorithm.

\section{REFERENCES}

Goodwin, S. D. \& Hartis, C. E. (2008). Central Nervous System Infection. (In: Wells, B. G., Schinghammer, T. L., Malone, P. M., Kolesar, J. M., Rotschafer, J. C., Dipiro, J. T., Pharmacotherapy Principle and Practice). USA: McGraw-Hill.

Heckenberg, S. G., Brouwer, M. C. \& Beek, D. V. (2014). Bacterial Meningits (In: J. Biller \& J. M. Ferro (ed.) Handbook of Clinical Neurology Volume $1213^{\text {rd }}$ ). Edinburgh: Elsevier.

Libert, C., Dejager, L. \& Pinheiro. (2010). The X Chromosomes in Immune Functions: When a Chromosome Makes a Difference. Nature Reviews Immunology; 10; 594-604. 
Lofmark, S., Edlund, C. \& Nord, C. N. (2010). Metronidazole is Still the Drug of Choice for Treatment of Anaerobic Infections. Clinical Infectious Diseases; 50; 16-23.

Lutsar, I. \& Friedland, I. R. (2000). Pharmacokinetics and Pharmacodynamics of Cephalosporin in Cerebrospinal Fluid. Drug Disposition; 39; 335343.

Mace, S. E. (2008). Acute Bacterial Meningitis. Emergency Medicine Clinics; 26; 281-317.

McGill, F., Heyderman, R. S., Panagiotou, S., Tunkel, A. R. \& Solomon, T. (2016). Acute Bacterial Meningitis in Adults. The Lancet; 6736; 1-12.

McIntyre, P. B., O'Brien, K. L., Greenwood, B. \& Beek, D. (2012). Effect of Vaccines on Bacterial Meningitis Worildwide. The Lancet; 380; 17031711.

Nau, R., Sorgel, F. \& Eiffert, H. (2010). Penetration of Drugs through the Blood-Cerebrospinal Fluid/Bood-Brain Barrier for Treatment of Central Nervous System Infections. Clinical Microbiology Reviews; 23; 858-883.

Paolo, A. D., Gori, G., Tascini, C., Danesi, R. \& Tacca, M. D. (2013). Clinical Pharmacokinetics of Antibacterials in Cerebrospinal Fluid. Clinical
Pharmacokinetics; 52; 511-542.

Prasad, K., Kumar, A. \& Singhal, T. (2007). Third Generation Cephalosporins Versus Conventional Antibiotics for Treating Acute Bacterial Meningitis. Hoboken: John Wiley \& Sons, Ltd.

Roos, K. L. \& Beek, D. V. (2010). Bacterial Meningitis (In: Roos K., Tunkel, A. (ed.), Handbook of Clinical Neurology). Amsterdam: Elsevier.

Shaban, L. \& Siam, R. (2009). Prevalence and Antimicrobial Resistance Pattern of Bacterial Meningitis in Egypt. Annals of Clinical Microbiology and Antimicrobials; 8; 1-10.

Tunkel, A. R., Calderwood, S. B. \& Thorner, A. R. (2017). Initial Therapy and Prognosis of Bacterial Meningitis in Adults. Amsterdam: Wolters Kluwer.

Tunkel, A. R. (2017). Clinical Features and Diagnosis of Acute Bacterial Meningitis in Adults. Amsterdam: Wolters Kluwer.

Tzanakaki, G. \& Mastrantonio, P. (2007). Aetiology of Bacterial Meningitis and Resistance to Antibiotics of Causative Pathogens in Europe and in the Mediterranean Region. International Journal of Antimicrobial Agents; 29; 621-629. 